\title{
Heading toward the future of pediatric heart failure with continuous-flow ventricular assist devices
}

\author{
Ryan R. Davies, MD
}

From the Nemours Cardiac Center, A.I. duPont Hospital for Children, Wilmington, Del; and Department of Surgery, Sidney Kimmel Medical College, Thomas Jefferson University, Philadelphia, Pa.

Disclosures: Author has nothing to disclose with regard to commercial support.

Received for publication May 26, 2017; accepted for publication May 31, 2017; available ahead of print June 29, 2017.

Address for reprints: Ryan R. Davies, MD, 1600 Rockland Rd, Wilmington, DE 19803 (E-mail: ryan.davies@ nemours.org).

J Thorac Cardiovasc Surg 2017;154:1356-7

$0022-5223 / \$ 36.00$

Copyright (c) 2017 by The American Association for Thoracic Surgery

http://dx.doi.org/10.1016/j.jtcvs.2017.05.097

Since 1984, when Dr Eric Rose performed the first successful pediatric heart transplant, ${ }^{1}$ transplantation has been the focus of therapy for medically refractory heart failure in children. The goal of mechanical circulatory support (MCS), whether with extracorporeal membrane oxygenation or ventricular assist devices (VADs), was to allow the child to survive until an allograft became available. For those candidates who survive the waitlist without endorgan damage and receive an allograft offer, long-term survival is excellent. $^{2}$

Many candidates, however, die before receiving an offer or suffer end-organ damage that increases early mortality. The waitlist mortality among pediatric heart candidates remains greater than $25 \%$, and there is a similar rate of mortality among recipients with end-organ dysfunction at transplant. Furthermore, some patients never become candidates: they are too sick, too noncompliant, or have systemic disease expected to limit their life expectancy (ie, cancer, muscular dystrophy). Historically, there were no options for these patients. The editorial by Dr Adachi in the current issue of the Journal provides a thorough, succinct, and informative review describing how the use of continuous-flow VADs in children may change this paradigm. $^{3}$

As the result of a variety of factors, including a more limited population leading to lower industry investment as well as the additional technical challenges of blood pumps at lower flows with greater relative surface area, the expansion of VADs to children has been slow. However, as Dr Adachi discusses, the field may be approaching a turning point. The availability of continuous-flow VADs suitable for use in children is an important component of this change (and the focus of the review). The review thoroughly addresses the myriad ways in which these devices have the potential to alter our use of MCS in children: improving outcomes overall and in children with congenital heart disease, enabling discharge, and providing effective longerterm support. There is little to add.

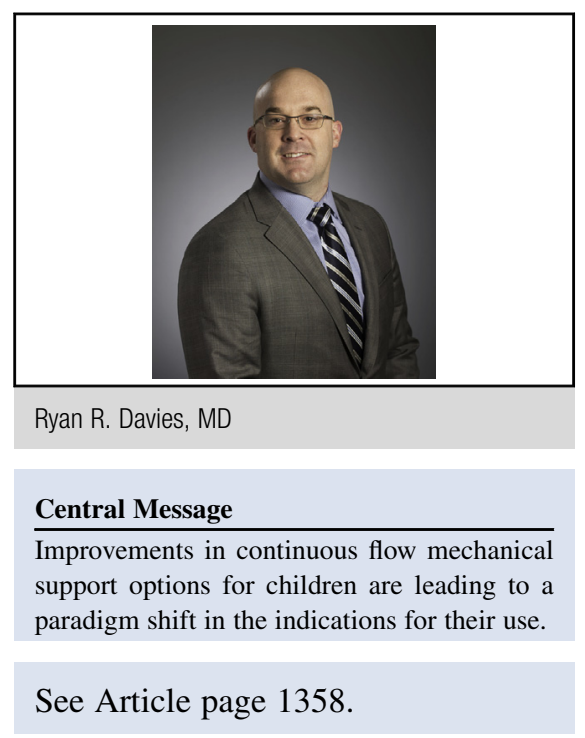

So instead I would focus on a theme that underlies the entirety of Dr Adachi's review. With increasing familiarity and improved outcomes among children supported by VADs (especially with continuous flow), MCS should no longer be viewed as a last-ditch effort to enable a child to survive to transplant. Further, a priori definition of the eventual outcomes of mechanical support: bridgeto-transplant, bridge-to-recovery, destination therapy, etc, is not instructive. MCS should instead be viewed as one option for the treatment of heart failure. The goals of support initiation should be tailored to the individual patient with the device implant indication only determined based on the expected risk/benefit profile for that patient. In other words, a patient's current transplant candidacy, although it may bear on the particular device selected, should not be a prerequisite for MCS candidacy.

Children may shift from being transplant candidates to not being candidates due to complications of MCS implantation; however, as noted in the review, devices may be a critical part of bridging a child through a period of psychosocial or medical challenges otherwise precluding transplant candidacy. Improvements in endorgan function and physical activity will improve transplant outcomes, but they are important goals independent of transplant candidacy. Many children may have better quality-of-life and better survival on a continuous-flow VAD than with transplantation. With a full understanding of MCS options and outcomes, 
practitioners can help children and families make the best choices for their care. As devices improve and the benefits of durable continuous-flow VADs become available to smaller and smaller children, the goal of MCS therapy should not be transplant candidacy alone but allowing children to live better and longer lives with or without a transplant.

\section{References}

1. Addonizio LJ, Rose EA. Cardiac transplantation in children and adolescents. $J$ Pe diatr. 1987;111:1034-8

2. Dipchand AI, Rossano JW, Edwards LB, Kucheryavaya AY, Benden C, Goldfarb S, et al. The registry of the International Society for Heart and Lung Transplantation: eighteenth official pediatric heart transplantation report-2015. J Heart Lung Transplant. 2015;33:985-95.

3. Adachi I. Continuous-flow ventricular assist device support in children: a paradigm change. J Thorac Cardiovasc Surg. 2017;154:1356-7. 